\title{
Determination of the Degree of Pain During Vaccination According to Wong Baker FACES
}

\author{
Ibrahim D Rudhani ${ }^{1}$, Naim Morina*2, ELEZI Gresa ${ }^{3}$ and Ahmet Avdulahu ${ }^{4}$ \\ ${ }^{1}$ Associate professor in Medical Faculty, Kosovo \\ ${ }^{2}$ Teaching assistant in Medical Faculty, Kosovo \\ ${ }^{3}$ Clinic of Hematology, UCCK Kosovo Hospital, Kosovo \\ ${ }^{4}$ Clinic of Nephrology and Hemodialysis UCCK Kosovo Hospital, Kosovo \\ *Corresponding author: Naim Morina, Clinic of Nephrology and Hemodialysis UCCK Kosovo Hospital Circlen.n. 10000 Pristina, \\ Kosovo
}

ARTICLE INFO

Received: April 16, 2020

Published: 幽 May 18, 2020

Citation: Ibrahim D Rudhani, Naim Morina, ELEZI Gresa, Ahmet Avdulahu. Determination of the Degree of Pain During Vaccination According to Wong Baker FACES. Biomed J Sci \& Tech Res 27(4)-2020. BJSTR. MS.ID.004548.

Keywords: Pain; Vaccination; Children

\section{Abstract}

Introduction: According to the International Association for the Study of Pain "Pain isunpleasant sensory and emotional experience associated with actual or potential tissue damage"Pain is the most common symptom presenting patients in primary care.

Purpose: The purpose of this study isto determine the pain scale in vaccinated children according to age and the size of the induration.

Methodology: The research conducted is a prospective and descriptive type analysis which includes data from January 2019 to June 2019.Determination of pain scale in vaccinated children was done according to the Wong-Baker scale.

Results: The study included 82 randomly selected cases over a 6 month period, starting from January 2019 to June 2019. Of these, 53.65\% (44 patients) were female and $46.34 \%$ (38 patients) they were men. According to the data collected, it has been concluded that children aged 3-4 months respond more strongly to the vaccine compared to those 2 months old.

Conclusion: Monitoring the scale of pain is difficult, as pain is a subjective experience and can vary from person to person. In our research we can conclude that children aged 3-4 months reacted more during vaccination compared to those who were 2 months old. The children 'cry' more during the second vaccine, while in the first one they were more confused and unresponsive.

\section{Introduction}

According to the International Association for the Study of Pain (IASP) "Pain isan unpleasant sensory and emotional experience associated with actual or potential tissue damage. Pain is the most common symptom presenting patients in primary care [1]. Pain occurs when the tissues are being damaged, and forces the personto react to remove the pain stimuli. Monitoring the scale of pain is difficult, as pain is a subjective experience and can vary from person to person. Failure to assess pain can affect quality of life and lead to increased hospitalization days [2].

\section{The purpose}

The purpose of this study is to determine the pain scale in vaccinated children, according to the mimicry - Wong-Baker Scale and determination of pain scaleby age, vaccine type and induration size. During treating health problems in primary health care, pain is the most commonly encountered symptom, which despite the rapid development of diagnostics and medical technology, still remains undiagnosed and not well treated. Therefore, it is of utmost importance to adopt pain assessment methods to achieve the most effective treatment of pain and its causes. 


\section{Methodology and Material}

The research is a prospective type analysis, descriptive-type, that includes data from January 2019 to June 2019. Determination of scale pain in vaccinated children was done according to the Wong-Baker scale.Data presentation was done using charts and graphs. The analytical and comparative statistical method was used. The total number of patients was divided by sex, age, size of skin induration after vaccination, and manifestation of pain during vaccination. The research data were obtained from the Main Family Medicine Center in Gjilan [3-5].

\section{Results}

The research includes 82 randomly selected cases over a period of 6 months, starting from 1st of January 2019 to 30 of June 2019. Of these, $53.65 \%$ ( 44 children) were female and $46.34 \%$ (38 children) were male(Table 1) (Figure 1). During this period in MFMC in Gjilan, 82 children were vaccinated, of which 23 cases (28.04\%) were 2 months of age, 21 cases (25.60\%) 3 months, 20 cases $(24.39 \%) 4$ months and 18 cases $(21,95 \%)$ were $12-18$ months(Table 2$)$ (Figure 2). According to the size of skin induration after vaccination, 31 (37.80\%) children responded with $3 \mathrm{~mm}$ induration, 17 (20.73\%) children with $5 \mathrm{~mm}$ induration, 19 (23.17\%) with $4 \mathrm{~mm}$ induration, 9 (10.97\%) with induration $2 \mathrm{~mm}$, and 4 (4.87\%) of children after vaccination did not have skin induration(Table 3) (Figure 3). According to the data collected, it has been concluded that children aged 3-4 months respond more strongly to the vaccine compared to those 2 months old. Also, children cry more when they receive the second vaccine, while they are confused and unresponsive during the first vaccine (Figure 4).

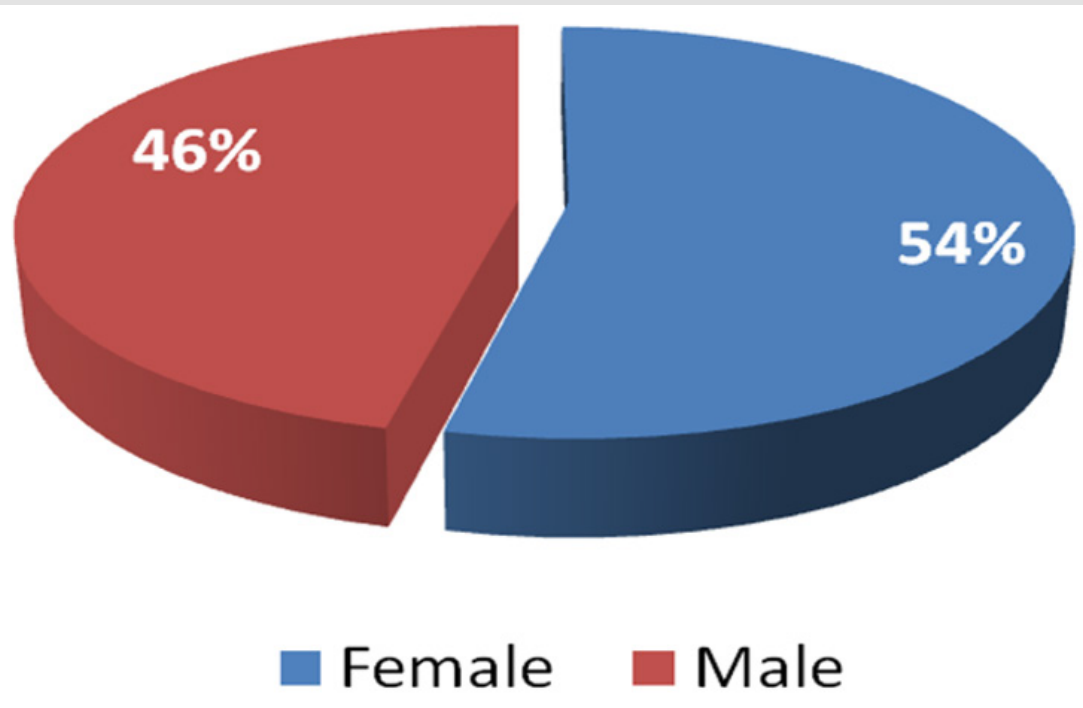

Figure 1: Graphic presentation of the study by gender.

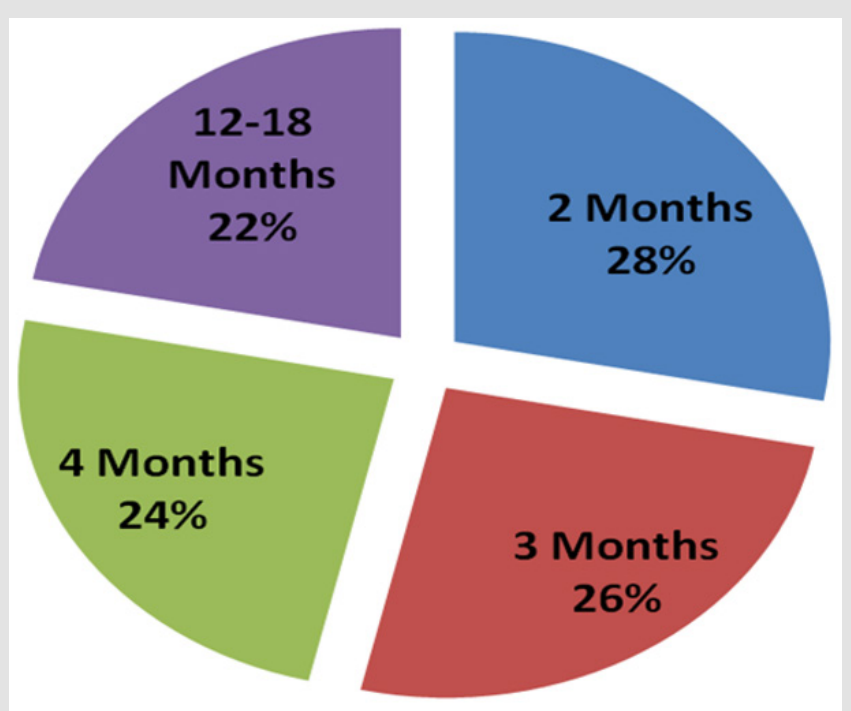

Figure 2: Graphic representation by age of vaccinated children. 


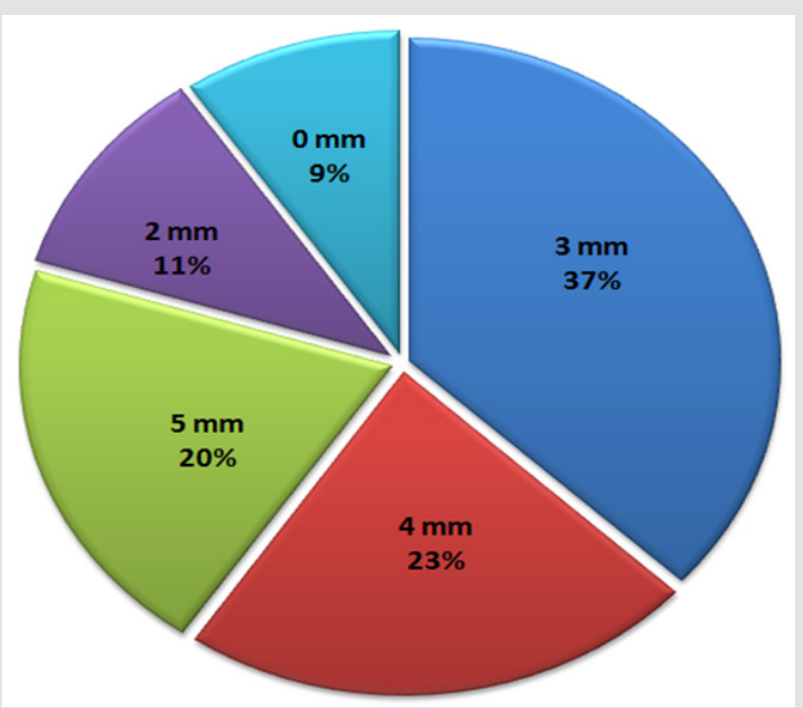

Figure 3: Graphical representation by induration size.

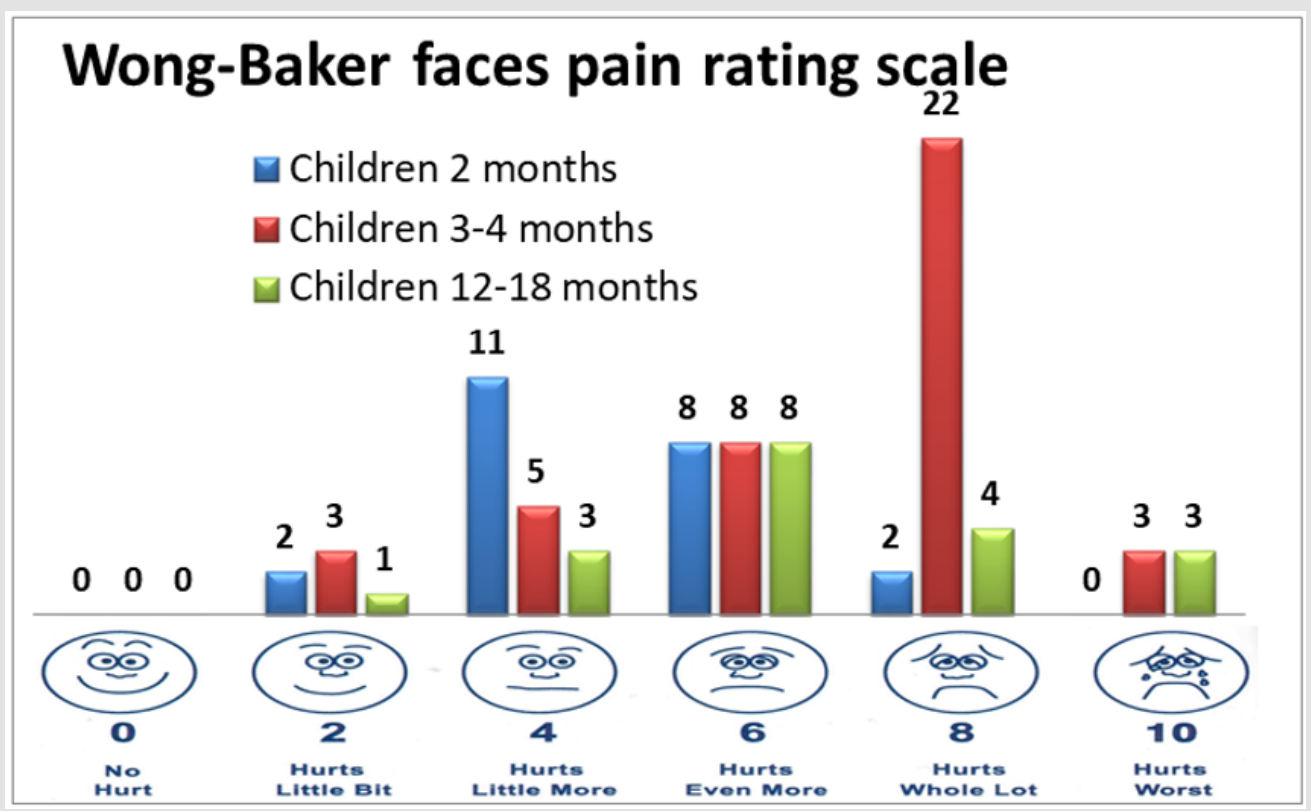

Figure 4: Graphical representation of pain manifestation during vaccine injection.

Table 1: Number of children included in the study.

\begin{tabular}{|c|c|c|}
\hline & No. of children & No. of children in \% \\
\hline Female & 44 & $53.65 \%$ \\
\hline Male & 38 & $46.35 \%$ \\
\hline Total & 82 & $100 \%$ \\
\hline
\end{tabular}

Table 2: Prepresentationof children by age vaccinated during January-June, 2019.

\begin{tabular}{|c|c|c|}
\hline Age & No. of children & No. of children in \% \\
\hline 2 Months & 23 & $28.04 \%$ \\
\hline 3 Months & 21 & $25.60 \%$ \\
\hline 4 Months & 20 & $24.39 \%$ \\
\hline $12-18$ Months & 18 & $21.95 \%$ \\
\hline
\end{tabular}


Table 3: Presentation the size of skin induration after vaccination.

\begin{tabular}{|c|c|c|}
\hline No. of children & No. of childrenin \% & Size of induration \\
\hline 31 & & $3 \mathrm{~mm}$ \\
\hline 19 & $23.17 \%$ & $4 \mathrm{~mm}$ \\
\hline 17 & $20.73 \%$ & $5 \mathrm{~mm}$ \\
\hline 9 & $10.97 \%$ & $2 \mathrm{~mm}$ \\
\hline 8 & $4.87 \%$ & $0 \mathrm{~mm}$ \\
\hline
\end{tabular}

\section{Discussion and Conclusion}

Monitoring the degree of pain is difficult, as pain is a subjective experience and can vary from person to person. Of the total number of 82 children surveyed, $18 \%$ responded with a pain scale $4 ; 35 \%$ responded with pain scale $6,9 \%$ of them responded with a scale of pain 8 , and $8 \%$ of them with a scale of pain 2 . That means children of age 3-4 months respond more strongly to the vaccine compared to those 2 months old. The children cry more during the second vaccine, while in the first one they were more confused and unresponsive.According to a study conducted in Canada by the Medical Research Council of Canada, a sample of 87 children found that ages 3 to 5 months manifest more pain during vaccination. It is worth noting that the two comparative studies used a common methodology such as the Wong-Baker mimicry scale and the VAS (Visual Analoug Scale) [6,7].

\section{References}

1. Karen Koch (2014) Assessing pain in primary care. Official journal of the South African Academy of Family Practice/Primary Care 54(1): 21-24.

ISSN: 2574-1241

DOI: 10.26717/BJSTR.2020.27.004548

Naim Morina. Biomed J Sci \& Tech Res

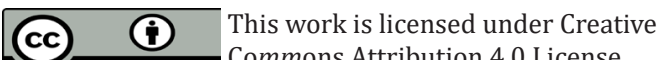

Submission Link: https://biomedres.us/submit-manuscript.php
2. Pathophysiology of the third, renewed and supplemented, Stjepan Gamulin, Marushiq Matko, Sllavko Kërvavicaiz 375.

3. Khalid W Al Quliti, Majed S Alamri (2015) Assessment of pain Knowledge, attitudes, and practices of health care providers in AlmadinahAlmunawwarah, Saudi Arabia. Neurosciences 20(2): 131136.

4. https://www.dreamstime.com/stock-illustration-nerve-response-topain-touch-noxious-receptors-skin-pathway-brain-via-spinal- cordthalamus-image 56635420

5. Dual Pathways for Transmission of Pain Signals into the Central Nervous System. Medical Physiology.

6. Sabu James (2013) Human pain and genetics: some basics. Br J Pain 7(4): 171-178.

7. Ludger Klimek, Karl Christian Bergmann, Tilo Biedermann, Jean Bousquet, Peter Hellings, et al. (2017) Visual analogue scales (VAS): Measuring instruments for the documentation of symptoms and therapy monitoring in cases of allergic rhinitis in everyday health care. Allergo J Int 26(1): 16-24.

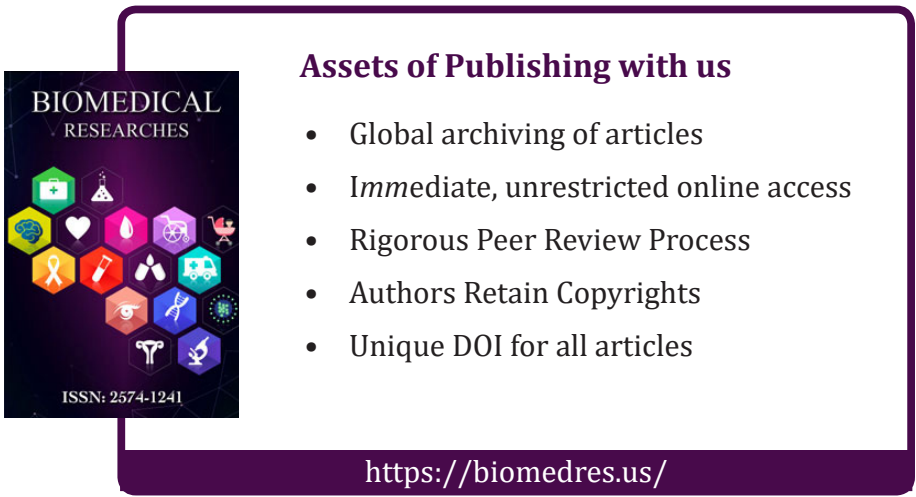

